\title{
CD4+ T-Lymphopenia in HiV Negative Tuberculous Patients at King Khalid University Hospital in Riyadh, Saudi Arabia
}

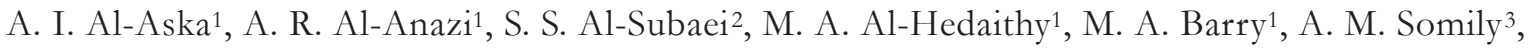 \\ F. Buba ${ }^{1}$, U. Yusuf 1 , N. A. Al Anazi ${ }^{1}$ \\ ${ }^{1}$ Department of Medicine, ${ }^{2}$ Department of Pediatrics, ${ }^{3}$ Department of Pathology, \\ College of Medicine and King Khalid University Hospital, King Saud University, Riyadh, Saudi Arabia
}

\begin{abstract}
Tuberculosis $(\mathrm{Tb})$ is a chronic infectious disease in which the cellular immunity (specifically CD4+ and CD8 lymphocytes) provides the most important defense in controlling infection. CD4 lymphopenia is a well-defined risk factor for the development of active tuberculosis in patients infected with Human Immunodeficiency Virus. In HIV - negative patients, CD4 and CD8 cell count suppression has been associated with $\mathrm{Tb}$ infection. Our study was designed to determine the baseline and post-treatment values of CD4 and CD8 in HIV negative patients diagnosed with active Tb in Saudi Arabian patients. We recruited twentyeight, non-HIV patients with tuberculosis for the study group comprising 16 males and 12 females with either disseminated or localized active $\mathrm{Tb}$ infection. Two control groups were selected - one of twentyone matched healthy controls and the second of fortytwo subjects from pool of controls of an ongoing study in same population for normal CD4 and CD8 counts. The baseline pre-treatment CD4 and CD8 counts in the study group were significantly lower than either control group. Specifically the mean \pm SD of CD4 counts were $556.79 \pm 298.81$ in the study group vs $1,132.38 \pm 259.90$ in control group 1 and 1,424.38 \pm 870.98 in control group 2 (p 0.000). Likewise the CD8 counts in the study group were 1,136.00 \pm 512.06 vs. $1,461.90 \pm 367.02$ in control group 1 and $1,495.90 \pm 565.32$ in control group 2 (p 0.000) respectively. After treatment of tuberculosis, the study patients experienced a significant increase in their mean \pm SD CD4 and CD8 cell counts, from 556.79 \pm 297.81 to $954.29 \pm 210.90$ for CD4 cells (p 0.005) and $1136.00 \pm 512.06$ to $1,316.54 \pm 286.17$ for CD8 cells (p 0.002). Analysis of study patients with disseminated disease found significantly lower CD4 cells (but not lower CD8 cells) compared to study patients with localized disease, both at baseline and after treatment. The mean \pm SD baseline CD4 cells were $247.60 \pm 187.80$ with disseminated vs $728.56 \pm 186.32$ for localized disease $(\mathrm{p}=0.000)$ which rose to 842.30 \pm 93.55 vs $1016.50 \pm 233.51(\mathrm{p}=0.033)$ respectively. We conclude that tuberculosis may be associated with CD4 and CD8 lymphopenia even in patients without human immunodeficiency virus infection, there was the tendency of recovery towards normality especially
\end{abstract}

of the CD4 and CD8 counts after treatment, and that disseminated disease is associated specifically with profound CD4 lymphopenia.

\section{INTRODUCTION}

Tuberculosis remains an infectious disease causing significant morbidity and mortality on a global scale. The fifteenth annual report of the World Health Organization [1] gave an estimate of the global burden of the disease caused by TB in 2009 as follows: 9.4 million new cases, prevalent cases of 14 million and deaths of 1.3 million and 0.38 million among HIV-negative and HIV positive people respectively.

The natural course of TB infection is basically determined by the ability of the host's immune system resulting in swift eradication, dormancy or failure, which leads to active disease [2]. Protective immunity to $\mathrm{TB}$ in humans relies upon both $\mathrm{CD} 4+$ and $\mathrm{CD} 8+$ T-cells through cell-mediated responses, allowing full eradication or control of infection [3]. The important contribution of CD4+ T- cells is especially obvious in HIV infection which by depletion of these subsets of cells predisposes infected individuals to reactivation of tuberculosis. It had previously been documented that $\mathrm{Tb}$ infection itself may cause a CD4 lymphopenia in patients not infected with HIV, sometimes with grave consequences [4]. It had also been demonstrated that the CD4 lymphoenia was potentially reversible with treatment [5]. The aim of this study was to determine CD4 and CD8 values of non-HIV tuberculosis patients at baseline and post treatment periods by flow cytometry.

\section{Material And Methods}

We enrolled a study population of twenty-eight randomly selected non- HIV infected patients with wide spectrum of active tuberculosis seen at the King Khalid University Hospital (KKUH), Riyadh over a one-year period. Eligible patients were enrolled based on compatible symptoms of TB and positive $\mathrm{My}-$ cobacterium tuberculosis based on Ziel -Nielsen smear and/or culture of relevant specimens as determined by the Bactec system and/ or Lowenstein-Jensen culture methods. The first control group of matched 
healthy controls was not infected with $\mathrm{Tb}$ confirmed by absence of history suggestive of tuberculosis, negative tuberculin tests and normal chest $\mathrm{x}$-rays. The second control group was derived from an ongoing study determining the normal range of $\mathrm{CD} 4$ and $\mathrm{CD} 8$ counts from healthy controls of the same population at KKUH. For this second control group, Quantiferon negativity was additionally used to exclude latent tuberculosis. Both subjects and controls were screened for HIV and were ensured negative using Enzymelinked immunosorbent assay (ELISA) and Recombinant immunoblot assay (RIBA). Patients and controls were excluded if they have the following conditions: any form of immunodeficiency syndromes, diabetes mellitus, chronic kidney disease and concurrent use of immunosuppressant medications. Informed consent was sought from both subjects and controls before enrollment. Baseline and post- treatment CD4/CD8 counts in recruited patients and baseline parameters of controls were recorded. Patients in the study group were treated for two months with isoniazid, rifampicin, pyrazinamide and ethambutol. The former two drugs were then continued to complete treatment of 6,9 , and 12 months for pulmonary, adenitis, and military/disseminated/meningitis respectively. Cure was determined by such parameters including resolution of fever, increase in weight, radiological resolution and decrease in erythrocytes sedimentation rate.

\section{FLOW CyTOMETRY STUdy}

Blood was collected in EDTA tubes and analyzed within 6 hours of storage for direct immunoflourescence stain. Twenty (20) ul of fluorochromes conjugated monoclonal antibody was added to $100 \mu$ l of whole blood in Falcon tube. The sample was then spun gently and incubated for 15 minutes in dark at a room temperature. The sample was further left for 10 minutes after adding $2 \mathrm{ml}$ of FACS lysing solution. Centrifugation was done at $500 \mathrm{x} g$ for 5 minutes followed by discarding of the supernatant. The cells pellet was then re-suspended in 2 cc of wash buffer. Fur- her centrifugation was done and cells were re-suspended in $0.5 \mathrm{cc}$ of paraformaldehyde for flow cytometric analysis. Acquisition was performed on FAC Scan (Becton Dickinson Immunocytometry System). CELL Quest Software BDIS on list mode data was then utilized to determine the lymphocyte gate by forward / side scatter characteristic. FLI/FL2 contour plots were finally employed for two-color analysis.

Recorded data was analyzed using SPSS version 16 Statistical package. Significance was determined at $\mathrm{p}$ value of 0.05 .

\section{RESULTS}

Twenty-eight patients were recruited for the study group, made up of 16 males and 12 females with a combined mean age of 40 (Range 17-69) years. Table 1 shows the composite data of their total white blood cells with mean + SD of 9,653.6 $\pm 5,602.3(95 \%$ confidence interval 7,436.5-11,900.4), lymphocytes 3,753.7 $\pm 304.4(2,549.4-4,958.0)$ and percentage lymphocytes $36.2 \pm 15.2(30.2-42.2)$ of the study patients. These values were within normal reference values in our laboratory. Baseline mean \pm SD CD4 counts of study patients (Table 2) were significantly lower at $556.79 \pm$ 297.81 versus $1132.38 \pm 259.90$ in control group 1 and $1424.38 \pm 870.98$ in control group 2 (pvalue 0.000). Likewise, CD 8 counts of study patients were significantly lower as at $1136.00 \pm 512.06$ compared with either of control groups at $1461.90 \pm 367.02$ and $1495.90 \pm 565.32$ respectively ( $\mathrm{p}$ value of 0.000 ). After treatment, the study group experienced significant improvement in CD4 and CD8 counts. The mean \pm SD count of CD4 cells went up from $556.79 \pm 297.81$ pretreatment up to $954.29 \pm 210.90$ after ( $\mathrm{p} 0.005$ ), while the CD8 cells were $1136.00 \pm 512.06$ and $1316.54 \pm$ 286.17 respectively (p 0.002). Patients with disseminated disease (miliary and localization in more than one tissue) showed significantly lower initial CD4 counts (Table 3) than localized form (Pulmonary or Adenitis), with mean \pm SD CD4 counts of $247.60 \pm 187.80$ versus $728.56 \pm 186.32$ (p value 0.000$)$. No significant dif-

Table 1. Composite Data of Total White Blood Cells (WBC), Lymphocytes and Percentage Lymphocytes among 28 patients of the Study Group.

\begin{tabular}{llll}
\hline Parameter & Total WBC & Lymphocytes & Percentage of Lymphocytes \\
\hline Mean & $9,652.6$ & $3,753.7$ & 36.2 \\
Standard Deviation & $5,602.3$ & 304.4 & 15.2 \\
95\% Confidence Interval & $7,436.5-11,900.4$ & $2,549.4-4,958.0$ & $30.2-42.2$ \\
\hline
\end{tabular}

Table 2. Comparison of Pretreatment versus Controls and Post-treatment in CD4 and CD8 Counts

\begin{tabular}{lll|lll}
\hline CD4 Counts & mean \pm SD & p Value & CD8 Counts & mean \pm SD & p Value \\
\hline Pretreatment & $556.79 \pm 297.81$ & 0.000 & Pretreatment & $1136.00 \pm 512.06$ & 0.000 \\
Controls 1 & $1132.38 \pm 259.90$ & & Controls 1 & $1461.90 \pm 367.02$ & \\
Controls 2 & $1424.38 \pm 870.98$ & 0.000 & Controls 2 & $1495.90 \pm 565.32$ & 0.000 \\
& & & & & \\
\hline Pretreatment & $556.79 \pm 297.81$ & 0.005 & Pretreatment & $1136.00 \pm 512.06$ & 0.002 \\
Post-treatment & $954.29 \pm 210.90$ & & Post-treatment & $1316.54 \pm 286.17$ & \\
\hline
\end{tabular}


Table 3. Comparison of Pretreatment and Post-treatment CD4 and CD8 Counts between Disseminated and Localized Diseases.

\begin{tabular}{lll|lll}
\hline Pretreatment CD4 Counts & mean \pm SD & p Value & Pretreatment CD8 Counts & mean \pm SD & p Value \\
\hline $\begin{array}{l}\text { Disseminated } \\
\text { Localized }\end{array}$ & $\begin{array}{l}247.60 \pm 187.80 \\
728.56 \pm 186.32\end{array}$ & 0.000 & $\begin{array}{l}\text { Disseminated } \\
\text { Localized }\end{array}$ & $994.70 \pm 549.12$ & 0.285 \\
\hline Post-treatment CD4 Counts & & & Post-treatment CD8 Counts & & \\
\hline $\begin{array}{l}\text { Disseminated } \\
\text { Localized }\end{array}$ & $842.30 \pm 93.55$ & 0.033 & $\begin{array}{l}\text { Disseminated } \\
\text { Localized }\end{array}$ & $136.61 \pm 388.39$ & \\
\hline
\end{tabular}

ferences in CD8 counts were found between patients with disseminated and localized forms of the disease. The post treatment value of CD4 counts in the disseminated disease remained lower than localized disease even after treatment at $842.30 \pm 93.55$ versus $1016.50 \pm 233.51(\mathrm{p}=0.033)$.

\section{DisCUSSION}

Humans acquire infection with Mycobacterium tuberculosis (MTB) commonly by inhaling the bacterium. Only a small number of bacilli need to enter distal alveoli of the human's lung to establish infection [6]. The alveolar macrophages form first line of defense against the inhaled droplets containing MTB [7]. Cellular-mediated immunity has a central role in the containment of TB. The mechanism involves rapid onset of Th1 cytokine response comprising interferon (IFN) $\gamma[8]$ and tumour necrosis factor (TNF)- $\alpha$ [9]. Furthermore, restricted mycobacterial growth in the lungs had recently been proposed through the induction of Th17 cells leading to production of IL-17 and IL-23. These cytokines cause inflammation and recruitment of Th1 cytokine producing cells $[10,11]$. CD8+ Tcells had also been shown to be essential in effective T-cell immune response [12].

The majority of patients successfully contain the primary infection within 2-10 weeks and go on to develop a vigorous delayed-type hypersensitivity (DTH) response [2]. In most healthy adults, adaptive immunity mediated by T- cells controls (but does not eradicate) $\mathrm{Tb}$ infection [13]. Thus ongoing protective immunity is required to maintain control over the bacilli. Immune failure of the adaptive immunity results in clinical tuberculosis [14]. The HIV pandemic provides direct evidence that loss of CD4 T-cell numbers and functions resulted in progressive primary infection, reactivation of endogenous $\mathrm{Tb}$ and enhanced susceptibility to re-infection [15].

Many studies had documented low CD4 counts in patients with tuberculous diseases, with few of them showing the reversibility of the counts towards normality after treatment. Similar to our study, Uppal et al [5] and Davoudi et al [16] found CD4 lymphopenia in patients with tuberculosis. Singhal and Banavalikar [17] also found low CD4 counts in both smear positive and smear negative patients with pulmonary tu-berculosis. In addition Kony et al [18] in a study in Senegal found extra-pulmonary and more especially miliary to have substantially lower CD4 counts. This concurs with our study which demonstrated significantly lower CD4 counts in disseminated than localized disease. Other studies had inferred that patients with low CD4 counts tend to have severe disease $[19,20]$ with profound incapacity.

Many hypotheses had been brought forward to explain the depletion of CD4+ which include unusual response to infections and homing of lymphocytes to affected tissue than in circulation [12]. Similar to our study, HIV- negative patients with TB and CD4+ Tlymphocyte depletion on presentation were shown to normalize their CD4+ cell counts with TB treatment [21]. Similarly, Bose et al [22] studied 21 cases of chronic, multi-bacillary pulmonary $\mathrm{TB}$ refractory to treatment and found that the decreased mean CD4/CD8 ratio normalized only in those patients who responded clinically and bacteriologically to therapy; in refractory cases, the ratio remained low.

Reports on CD8 counts in HIV-negative patients with TB had been conflicting. Shijubo et al [23] found significantly decreased CD8 cells, which is similar to our finding of significantly lower CD8 in patients as compared with controls. Davoudi et al [16] found lower number of CD8 cells in patients with severe disease like meningitis/miliary forms of TB as compared with controls. The reversibility of CD4 lymphopenia with successful therapy as found in our study was also demonstrated in various studies [5, 21, 22].

In conclusion, our study found significantly lower CD4 and CD8 counts among Tb infected HIV negative patients as compared with controls. The post-treatment CD4 counts demonstrated the tendency towards recovery to normal values. Patients with disseminated disease had much lower CD4 values than localized forms, with a delay of returning towards normality.

\section{REFERENCES}

1. Global tuberculosis control: WHO report 2010.www.who.int.

2. Ducati RG, Ruffino-Netto A, Basso L, Santos DS. The resumption of consumption. A review on tuberculosis. Mem Inst. Oswaldo Cruz 2006; 101: 697-714.

3. Rahman S, Gudetta B, Fink J, Granath A, Ashenafi S, Aseffa A, Derbew M, Svensson M, Andersson J, Brighenti SG. Compartmentalization of immune responses in human tuberculosis: Few CD8+ effector T-cells but elevated levels of Fox P3+ regulatory T-cells in the granulomatous lesions. Am J Pathol 2009; 176: 2211-24.

4. Aziz S, AlAnazi A R, Al-Hedaithy M A, Al Shobaili, HA, Al Aska AI. Mycobacterium Tuberculosis and CD4+ Tlymphocytopenia. A Grave Combination. Saudi Med J 2005; 10: 1655-7. 
5. Uppal SS. Tewari SC, Verma S, Dhot PS. Com-parison of CD4 and CD8 Lymphocyte Counts in HIV-negative Pulmonary TB Patients with Those in Normal Blood Donors and the Effect of Antitubercular Treatment: HospitalBased Flow Cytometric Study. Cytometry Part B (Clinical Cytometry) 2004; 61B:20-6.

6. Boom WH, Canady DH, Fulton SA, Gehring AJ, Rojas RE, Torres M. Human immunity to M. Tuberculosis; T cells subsets and antigen processing. Tuberculosis 2003; 83:98-106.

7. Balaji KN, Schwander SK, Rich EA, Boom WH. Alveolar macrophages as accessory cells for human gamma delta T-cells activated by Mycobacterium tuberculosis. J Immunol 1995; 154:59-68.

8. Newport MJ, Huxley CM, Huston S, Hawrylowicz CM, Oostra BA, Williamson R, Levin M. A mutation in the interferon-gamma-receptor gene and susceptibility to mycobacterial infection. N Engl J Med 1996; 335:1941-9.

9. Keane J, Gershon S, Wise RP, Mirabile-Levens E, Kasznica J, Schwieterman WD, Siegel JN, Braun MM. Tuberculosis associated with infliximab, a tumour necrosis factor alpha-neutralizing agent. N Engl J Med 2001; 345: 1098-104.

10. Lockhart E, Green AM, Flynn JL. IL-17 production is dominated by gamma delta T-cells rather than CD4 Tcells during Mycobacterium tuberculosis infection. J Immunol 2006; 177:4662-9.

11. Khader SA, Bell GK, Pearl JE, Fountain JJ, RangelMoreno J, Cilley GE, Shen F, Eaton SM, Gaffen SL, Swain SL, Locksley RM, Haynes L, Randall TD, Cooper AM. IL-23 and IL-17 in the establishment of protective pulmonary CD4+ T-cell responses after vaccination and during Mycobacterium tuberculosis challenge. Nature Immunol 2007; 8:369-77.

12. Lewinsohn DA, Heinzel A, Garadner JM et al. Mycobacterium tuberculosis specific CD8 T-cell preferentially recognizes heavily infected cells. Am J Resp Crit Care Med 2003; 168: 1346-52.

13. Edwards D, Kirkpatrick CH. The immunology of mycobacterial diseases. Am Rev Resp Dis 1992; 146:121621.

14. Montes SJ, Gamban JF, Pacheo CM, Cerda MR. Cellular immune response in Tuberculosis: Analysis of T-lymphocyte and their subsets, B-lymphocytes and natural cytotoxic cells in different tuberculosis states and body fluids. Rev Clin Exp 1996; 196:223-7.
15. Raviglione MC, Snider Jr. DE, Kochi A. Global epidemiology of tuberculosis. Morbidity and mortality of worldwide epidemic. JAMA 1995; 273:220-6.

16. Davoudi S, Rasoolinegad M, Younesian M, Hajiabdolbaghi M, Soudbakhsh A, Jafari S, Emadikouchak H, Mehrpouya M, Lotfi H. CD4+ cell counts in patients with different clinical manifestations of tuberculosis. Braz J Infect Dis 2008; 12:483-6.

17. Singhal M, Banavalikar JN. Peripheral blood T-lymphocytes subpopulations in patients with tuberculosis and the effect of chemotherapy. Tubercle 1989; 70: 171-8

18. Kony SJ, Hane AA, Larouze B et al. Tuberculosis-associated severe CD4+ T-lymphocytopenia in HIV - seronegative patient from Dakar. J Infect 2000; 41:167-71.

19. Jone BE, Oo MM, Taikwel EK et al. CD4+ cell count in human immunodefieciency virus-negative patients with tuberculosis. Clin Infect 1997; 24:988-91.

20. Pilheu JA, De Salvo MC, Gonzales J, Rey D, Elias MC, Ruppi MC. CD4+ T-lymphopenia in severe pulmonary tuberculosis without evidence of human immunodeficiency virus infection. Int J Tuberc Lung Dis 1997; 1:422-6.

21. Jurrett GS, Telzac EE. Normalization of CD4+ T-lymphocyte depletion in patients without HIV infection treated for tuberculosis. Chest 1994; 105:1335-7.

22. Bose M., Gupta A, Banavalikar JN, Saha K. Dysregulation of homeostasis of blood T-lymphocyte subpopulations persists in chronic multibacillary pulmonary tuberculosis patients refractory to treatment. Tuberc Lung Dis 1995; 76:59-64.

23. Shijubo N, Nakanishi F, Hirasawa M, Sigehara K, Sasaki $\mathrm{H}$, Asakawa M, Suzuki A. Phenotypic analysis in peripheral blood lymphocytes of patients with pulmonary tuberculosis. Kekkaku 1992; 67: 581-5.

Received: January 6, 2011 / Accepted: March 16, 2011

Address for correspondence:

Prof. Abdulkarim Al-Aska

Consultant in Infectious Diseases Division

Supervisor, Infection Control Department

Department of Medicine (38)

King Khalid University Hospital

P.O. Box 7805

Riyadh 11472

Saudi Arabia

E-mail: prof_alaska2004@yahoo.com 